\title{
The genetic basis of emotional behaviour in mice
}

\author{
Saffron AG Willis-Owen ${ }^{* 1}$ and Jonathan Flint ${ }^{1}$ \\ ${ }^{1}$ Wellcome Trust Centre for Human Genetics, Roosevelt Drive, Headington, Oxford, UK
}

The last decade has witnessed a steady expansion in the number of quantitative trait loci (QTL) mapped for complex phenotypes. However, despite this proliferation, the number of successfully cloned QTL has remained surprisingly low, and to a great extent limited to large effect loci. In this review, we follow the progress of one complex trait locus; a low magnitude moderator of murine emotionality identified some 10 years ago in a simple two-strain intercross, and successively resolved using a variety of crosses and fear-related phenotypes. These experiments have revealed a complex underlying genetic architecture, whereby genetic effects fractionate into several separable QTL with some evidence of phenotype specificity. Ultimately, we describe a method of assessing gene candidacy, and show that given sufficient access to genetic diversity and recombination, progression from QTL to gene can be achieved even for low magnitude genetic effects.

European Journal of Human Genetics (2006) 14, $721-728$. doi:10.1038/sj.ejhg.5201569

Keywords: mouse; emotionality; quantitative trait locus; QTL

\section{Introduction}

Emotionality is a psychological trait of complex aetiology, which moderates an organism's response to stress. Behavioural evidence of emotionality has been documented across a wide range of taxa from amphibians to rodents, and higher mammals; both in terms of a fear-like avoidance of perceived threats (eg predator-prey interactions and other environmental dangers), ${ }^{1}$ and enduring personality-like variation in sensitivity to stress. ${ }^{2}$ While evidence has only recently begun to emerge in favour of a capacity for non-human animals (including rodents) to experience $^{3}$ positive mood states, it is now accepted that a variety of species are likely possess an evolutionarily conserved capacity for fear and anxiety.

Emotionality, like other complex traits, is thought to result from the cumulative superimposition of low magni-

*Correspondence: Dr SAG Willis-Owen, Wellcome Trust Centre for Human Genetics, Roosevelt Drive, Headington, Oxford, OX3 7BN, UK. Tel: + 441865 287510; Fax: + 441865 287501;

E-mail: saffron.willis-owen@well.ox.ac.uk

Received 16 August 2005; revised 9 November 2005; accepted 10 November 2005 tude genetic effects and their interactions (both with other genetic loci (ie epistasis) and nongenetic (environmental) factors) ultimately producing a quasi-continuously distributed phenotype. As a combined consequence of the small individual genetic effects and their multifaceted patterns of moderation, genetic effects which contribute to variation in emotionality have, as in other complex traits proved remarkably difficult to identify.

The mouse exhibits a number of attributes, which may be useful to genetic research. These include a short gestation period, an early puberty, a short oestrus cycle and a tendency to produce large litters. The mouse genome is well characterised, ${ }^{4}$ containing around 22000 predicted genes, about $80 \%$ of which have a single identifiable human orthologue. These factors, along with a capacity for directed mating and rigid environmental control render the mouse an invaluable tool for complex trait dissection, with additional potential relevance towards human disease pathology. This relevance is illustrated through observations of mouse-human quantitative trait loci (QTL) concordance across a range of (primarily physiological) phenotypes (such as high-density lipoprotein (HDL) 
cholesterol concentrations ${ }^{5}$ ). While it is less likely that behavioural QTL will colocalise across species (not least due to difficulties in phenotype translation), it remains plausible that a small number of behavioural mechanisms, which carry a significant survival advantage may be conserved through evolution, and as such may depend, at least in part, on the same underlying genes.

\section{Emotionality in mice}

A range of behavioural phenotypes are currently utilised as informative measures of emotional reactivity in mice. These measures are founded on principals of avoidance, autonomic activation, and behavioural inhibition (the discontinuation of species-typical behaviours such as grooming, exploration and consumption in anxiogenic environments). These measures can be derived from a variety of paradigms, the most widely used of which is the open-field apparatus; a circular white, brightly lit and fully enclosed arena, within which behaviour can be remotely monitored.

Defecation and ambulation in the open-field exhibit a negative correlation. ${ }^{6,7}$ Since these two measures are not thought to be under the control of the same peripheral nervous system, it follows that their consistent inverse relationship is likely to reflect the action of a central coordinating mechanism or psychological trait (such as anxiety). ${ }^{8}$ Based on observations that intense fear can result in defecation, urination and immobility in humans, those animals found to demonstrate a combination of behavioural inactivity and heightened defecation have historically been considered to be more fearful or emotionally reactive. Consistent with this interpretation, repeated test exposures in the open-field result in a reduction in defection and decreased avoidance of the central (anxiogenic) areas $^{9}$ (ie a habituation).

\section{The emotionality profile and phenotype heterogeneity}

In addition to the open field, a number of other behavioural tests are available for the assessment and/or characterisation of an animal's emotionality profile. Those which we will pursue in this review include the elevated plus maze (EPM) and light-dark box (two environments consisting of contrasting anxiogenic (light and open) and safe (dark and enclosed) spaces); fear conditioning (evaluating an animal's behavioural response to cues or contexts previously associated with a negative experience (either in terms of avoidance or immobility)); the forced swim and tail suspension tests (measures of immobility in response to unavoidable aversive situations), and acoustic startle response. Although the measures derived from these tests are broadly consistent with one another, with for example behaviour in the EPM successfully predicting performance in other models of anxiety, ${ }^{10}$ there is some evidence that behaviour across these tests can be divided into a small number of genetically separable dimensions.

A recent principal components analysis of over 100 behavioural phenotypes in nearly 1700 mice identified five genetically separable composite measures of anxiety. These include: (i) activity suppression in 'safe areas', (ii) avoidance of anxiogenic areas, (iii) suppression of rearing, (iv) latency to enter novel areas, and (v) autonomic activity in novel environments. Between 4 and 6 QTL were found to contribute towards variance on each measure, with only about $20 \%$ of loci contributing $>2 \%$ of phenotypic variance to any given trait. These observations are consistent with previous multivariate mapping studies which have shown that a proportion of QTL in both mice $^{11}$ and rats ${ }^{12}$ exhibit characteristic ethological profiles which transcend test type, and can be replicated across intercrosses.

\section{Methods of mapping emotionality QTL in mice}

Inbred mouse strains exhibit large differences in emotionality. ${ }^{10,13,14}$ These differences can be exploited for the purposes of quantitative trait mapping through the construction of crosses between phenotypically divergent progenitor strains, and the subsequent use of directed breeding strategies with or without phenotype selection. As a general principal these approaches aim to maximise the level of genetic diversity at informative loci, and increase the number of recombination events intervening between genotyped markers and the QTL. Given an infinite marker density, crosses which contain higher levels of progenitor diversity, and which are separated from the parental strains by a larger number of meioses will provide the highest level of mapping resolution.

Several variations on this strategy exist, including the backcross and $\mathrm{F}_{2}$ intercross, recombinant inbred lines (RILs), chromosome substitutions, recombinant congenics and heterogeneous stocks (HS). The backcross and $\mathrm{F}_{2}$ intercross are the most widely used of these strategies. Two inbred strains (usually, but not necessarily with contrasting phenotypes) are crossed, the offspring genotyped and a test of the association between genotypic and phenotypic variation is performed. RILs involve a cross between two inbred strains, but in this case the $F_{2}$ generation are randomly intercrossed and inbred for around 20 generations yielding a diverse panel of inbred lines containing varying quantities of the two progenitor genomes. QTL can then be mapped by comparing the phenotypes of these lines, and establishing specifically which chromosomal regions they have in common.

The chromosome substitution method of phenotype analysis represents an alternative first stage approach towards QTL detection. Single chromosomes from one inbred strain are introgressed into the background of 
another by selective breeding, yielding a panel of inbred lines, which are genetically identical but for one chromosome. These lines can then be phenotyped for localisation of a QTL to the level of single chromosomes, and subsequently intercrossed to produce single chromosome $\mathrm{F}_{2} \mathrm{~S}$ with an enhanced mapping resolution and pure genetic background. Recombinant congenics are inbred lines, which contain a small proportion of one parental genome (the donor) relative to another (the recipient), typically produced by mating two inbred strains, backcrossing the descendents to one parental strain, and undertaking inbreeding without selection. Finally, HS are generated from a larger number of inbred strains (usually 8), which have been successively intercrossed for maximal diversity, and maintained over multiple generations through a program of pseudo-random mating. Of all the approaches discussed this method yields the greatest improvement in mapping resolution, but also necessitates an increase in maker density. Given current genotyping costs it may therefore prove more economical to utilise HS methodologies only once broad chromosomal regions have been identified, thereby limiting the number of markers required for QTL localisation (Figure 1).

\section{Isolating broad regions of genetic involvement}

The genetic mapping of rodent emotionality has historically focused predominantly on $\mathrm{F}_{2}$ intercross strategies; derived either from phenotypically diverse inbred strains, or intercross progeny which have been subject to bidirectional selection over multiple generations and inbred to produce contrasting lines. To date there have been at least 13 attempts to map mouse emotionality using an $F_{2}$ intercross strategy, ${ }^{8,15-26}$ relative to just one attempt using a backcross, ${ }^{27}$ two using RILs, ${ }^{28,29}$ one using chromosome substitution strains ${ }^{30}$ and one using recombinant congenics. ${ }^{28}$ Together these approaches have identified genome-wide significant linkage peaks (as determined either by permutation or application of the Lander and Kruglyak guidelines $^{31}$ ) on 17 of the 19 mouse autosomes, and on one of the two sex chromosomes (chromosome X). Plot 1 (below) illustrates the distribution of genome-wide significant LOD (logarithm of the odds) scores (at $\alpha=0.05$ ), which are available in the literature to date for those phenotypes described above. Regions which attained genome-wide significance only when mapped in parallel with other genetic cofactors $\left(\mathrm{eg}^{28}\right)$ were excluded from this analysis, and likewise where data from a single cross and phenotype had been presented in more than one publication, only original findings were included.

This plot demonstrates a clustering of genome-wide significant LOD scores on chromosomes 1, 15 and 18, with the largest quantity of evidence (a total of 41 linkage peaks) pointing towards the presence of one or more QTL on chromosome 1. Simulations have shown that, depending on the size of the genotyped population, the extent of marker spacing and magnitude of QTL effect, the location of linkage peaks can fluctuate up to 20-30 centimorgan (cM) from the true locus, ${ }^{32-34}$ and consistent with this observation over $80 \%$ of the genome-wide significant LOD
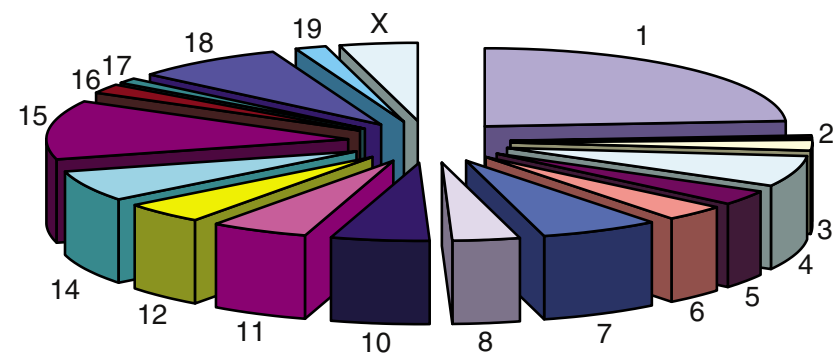

Plot 1 The distribution of significant anxiety-related LOD scores across the mouse genome by chromosome. This plot shows the number of genome-wide significant emotionality-related linkage peaks identified in the mouse to date, separated by chromosome.

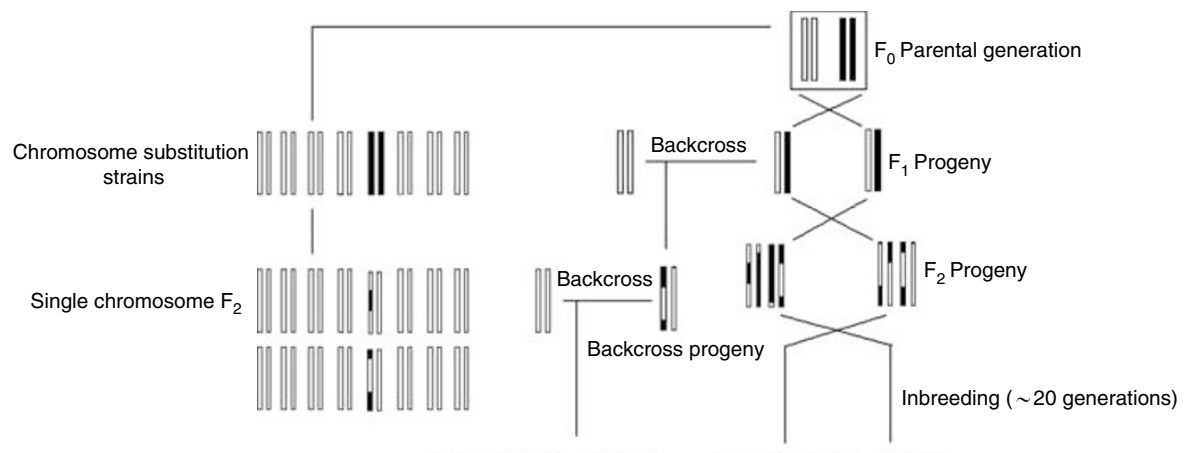

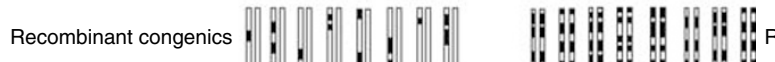

II. II II Recombinant inbred lines

Figure 1 Approaches to mapping a quantitative trait. This figure illustrates the various crosses utilised in the genetic mapping of murine emotionality. 
scores reported on chromosome 1 are located within a $30 \mathrm{cM}$ interval $(73-103 \mathrm{cM})$. However, from these data, which have been derived from multiple distinct strain contrasts and a range of different phenotypes, it is not possible to establish to what extent these peaks reflect common underlying QTL. Proximity alone is insufficient to enable a judgement of genetic equivalence, particularly in complex traits where single apparently large-effect QTL have often been found to fractionate into a multitude of smaller genetic effects.

\section{Focusing on chromosome 1}

The first evidence in favour of an emotionality locus on mouse chromosome 1 was derived from an $\mathrm{F}_{2}$ intercross of the DeFries strains; ${ }^{7}$ a set of phenotypically divergent inbred lines originally generated from a cross between C57BL/6J (a nonanxious strain) and BALB/CJ (an anxious strain), and then selected for trait extremity over multiple generations. Two of these lines (H1a and L1a) were then intercrossed, and the phenotypically most extreme progeny analysed across 84 microsatellite markers and four correlated measures of emotionality. In this way an emotionality QTL was identified on chromosome 1 located between markers D1MIT218 and D1MIT293 (spanning an interval of $65.6 \mathrm{Mb}$ ). The locus affected all four of the collected behavioural measures including both defecation and ambulation in the open-field, and entries into the open arms of the EPM. ${ }^{8}$

Similar analyses have since been carried out in a replicate population of the DeFries H1-L1 intercross progeny (H1b and L1b), ${ }^{23}$ a second intercross between the remaining two DeFries strains (H2 and L2), ${ }^{23}$ and a combined sample of two data sets (including over 1600 animals). ${ }^{24}$ These analyses have consistently identified a linkage peak between 72 and $82 \mathrm{cM}$ on mouse chromosome 1, using a range of primarily locomotor phenotypes including ambulation and defecation in the open-field, the number of open-arm entries in the EPM, the number of light-dark transitions made in the light-dark box, and the total amount of time spent in the light area. Consistent with these observations, a recent multivariate analysis of the complete DeFries data set showed that this chromosome 1 locus (located between 74 and $78 \mathrm{cM}$ ) operates in a phenotype specific manner, influencing a combination of safe-area ambulation and autonomic activity, and alone accounting for $4-10 \%$ of total activity variance within each apparatus. ${ }^{35}$

These data provide a relatively tight estimate of QTL location, and a homogenous description of QTL effect. However, all the evidence discussed thus far has been derived from a single inbred strain contrast between $\mathrm{BALB} / \mathrm{cJ}$ and $\mathrm{C} 57 \mathrm{BL} / 6 \mathrm{~J}$. This limitation on the level of genetic diversity may mean that a proportion of QTL, that is, those which do not segregate between BALB/CJ and C57BL/6J, or which exert opposing effects on the phenotype despite association with the same allele, will not have been detected. Table 1 provides a list of those genome-wide significant linkage peaks, which have been detected on mouse chromosome 1 to date. These linkage peaks have an average effect size of $6.2 \%$ (with a range of $1.1-21 \%$ ), and vary in location between 30 and $103 \mathrm{cM}$.

The use of additional genetic contrasts and phenotypes has led to a considerable expansion of the implicated regions, and a reduced homogeneity of effect. That is, QTLs on chromosome 1 have now also been shown to influence fear conditioning, activity in threatening areas and exploratory (rearing) behaviour, and furthermore, several potentially separable clusters of linkage peaks are now visible. Plots 2 and 3 illustrate the distribution of linkage peaks across chromosome 1 stratified both by phenotype and strain contrast. While there is no clear phenotypedependent division between loci (short of a predominant emphasis on activity-based phenotypes), different strain contrasts seem to have isolated distinct linkage peaks. One cluster of peaks located between 72 and $82 \mathrm{cM}$ on chromosome 1 appears to result from a contrast between $\mathrm{C} 57 \mathrm{BL} / 6 \mathrm{~J}$ on the one hand, and $\mathrm{A} / \mathrm{J}, \mathrm{C} 3 \mathrm{H} / \mathrm{HeJ}$ and $\mathrm{BALB} / \mathrm{cJ}$ on the other. In contrast, a second group of peaks located more distally between 93 and $103 \mathrm{cM}$ appears to result from a contrast between only two strains $(\mathrm{C} 57 \mathrm{BL} / 6 \mathrm{~J}$ and $\mathrm{A} / \mathrm{J})$, and a third cluster located more proximally $(49-54 \mathrm{cM})$ reflects a contrast between $\mathrm{C} 57 \mathrm{BL} / 6 \mathrm{~J}$ and both $\mathrm{C} 3 \mathrm{H} / \mathrm{HeJ}$ and 129SvEvTac. Furthermore, while the chromosome 1 locus represents the best replicated QTL for any mouse behaviour, a proportion of investigations have also failed to identify a QTL in the region $\left(\mathrm{eg}^{36}\right)$.

\section{Fine mapping of the chromosome 1 locus}

While whole-genome mapping of two-strain intercrosses represents an effective strategy for the identification of QTL, accurate localisation (sufficient to enable molecular cloning) requires a higher level of resolution. Incorporating multiple inbred strains into a single heterogeneous stock, which has been maintained over multiple generations (accumulating recombinants) provides a both controlled and powerful method for the identification of QTL, which segregate in different ways between different strains. To date two HS have been utilised for the fine mapping of murine emotionality; the Boulder HS and the Northport HS. The older of these stocks (the Boulder HS) was generated from C57BL/6, BALB/c, RIII, AKR, $\mathrm{DBA} / 2$, Is, $\mathrm{A} / \mathrm{J}$ and $\mathrm{C} 3 \mathrm{H}$, and had been bred for more than 58 generations at the time it was used for genetic mapping. Theoretically, the stock should offer a greater than 30-fold improvement in mapping resolution relative to $\mathrm{F}_{2}$ intercross strategies. ${ }^{37}$ 
Table 1 Evidence for emotionality locus/loci on mouse chromosome 1

\begin{tabular}{|c|c|c|c|c|c|c|c|c|}
\hline Phenotype & Method & Strains & $n$ & $\begin{array}{c}\% \\
\text { Genotyped }\end{array}$ & $\begin{array}{c}\text { Distance } \\
\text { (cM) }\end{array}$ & $\begin{array}{c}\text { Peak } L O D \\
\text { score }\end{array}$ & $\begin{array}{c}\% \\
\text { Variance }\end{array}$ & Reference \\
\hline FC: altered context & $B C$ & $\mathrm{C} 57 \mathrm{BL} / 6), \mathrm{C} 3 \mathrm{H} / \mathrm{HeJ}$ & 473 & 11 & 49 & 3.31 & NR & Caldarone et $\left.a\right|^{27}$ \\
\hline FC: altered context & $\mathrm{BC}$ & $\mathrm{C} 57 \mathrm{BL} / 6), \mathrm{C} 3 \mathrm{H} / \mathrm{HeJ}$ & 473 & 11 & 78.9 & 3.42 & NR & Caldarone et $a 1^{27}$ \\
\hline FC: context & $\mathrm{BC}$ & $\mathrm{C} 57 \mathrm{BL} / 6 \mid, \mathrm{C} 3 \mathrm{H} / \mathrm{He}$ & 473 & 11 & 30 & 5.14 & 6.2 & Caldarone et $\left.a\right|^{27}$ \\
\hline FC: context & $\mathrm{BC}$ & $\mathrm{C} 57 \mathrm{BL} / 6 \mathrm{~J}, \mathrm{C} 3 \mathrm{H} / \mathrm{HeJ}$ & 473 & 11 & 49 & 4.32 & NR & Caldarone et $a l^{27}$ \\
\hline FC: context & $\mathrm{BC}$ & $\mathrm{C} 57 \mathrm{BL} / 6 \mid, \mathrm{C} 3 \mathrm{H} / \mathrm{He}$ & 473 & 11 & 78.9 & 4.76 & NR & Caldarone et $a l^{27}$ \\
\hline EPM: OAE & $\mathrm{F} 2$ & Defries (H1a, L1a) & 879 & 22 & 100 & 9 & 21 & Flint et $\left.a\right|^{8}$ \\
\hline OFT: OFA & F2 & Defries (H1a, L1a) & 879 & 22 & 74 & 13.4 & 9.2 & Flint et $a l^{8}$ \\
\hline OFT: OFD & F2 & Defries (H1a, L1a) & 879 & 22 & 80 & 5.6 & 5.3 & Flint et $a l^{8}$ \\
\hline OFT: CT (5 min) & F2 & $\mathrm{A} / \mathrm{J}, \mathrm{C} 57 \mathrm{BL} / 6 \mathrm{]}$ & 518 & 12 & 73.2 & 7.73 & 6.8 & Gershenfeld and Paul $^{18}$ \\
\hline OFT: OFA (novel, $5 \mathrm{~min}$ ) & $\mathrm{F} 2$ & $\mathrm{~A} / \mathrm{I}, \mathrm{C} 57 \mathrm{BL} / 6 \mathrm{~J}$ & 518 & 12 & 100 & 7.1 & 6.3 & Gershenfeld et $a l^{17}$ \\
\hline OFT: $\mathrm{R}$ (novel $5 \mathrm{~min}$ ) & $\mathrm{F} 2$ & $\mathrm{~A} / \mathrm{l} \mathrm{C} 57 \mathrm{BL} / 6$ & 518 & 12 & 79 & 4.5 & 5.9 & Gershenfeld et al $1^{17}$ \\
\hline OFT: R (habituated, $5 \mathrm{~min}$ ) & $\mathrm{F} 2$ & $\mathrm{~A} / \mathrm{J}, \mathrm{C} 57 \mathrm{BL} / 6 \mathrm{]}$ & 518 & 12 & 102 & 5.8 & 5.4 & Gershenfeld et al ${ }^{17}$ \\
\hline OFT: OFA (first $15 \mathrm{~min}$ ) & $\mathrm{F} 2$ & C57BL/6), 129SvEvTac & 289 & 100 & 54 & 3.72 & 6 & Kelly et $a l^{19}$ \\
\hline OFT: OFA (5 min) & F2 & C57BL/6], 129 SvEvTac & 289 & 100 & 54 & 4.11 & 6 & Kelly et $a l^{19}$ \\
\hline LD box: latency & $\mathrm{F} 2$ & C57BL/6], CSS-1 & 91 & 100 & 93 & 3.3 & NR & Singer et $a l^{21}$ \\
\hline LD box: light box time & F2 & C57BL/6I, CSS- 1 & 91 & 100 & 103 & 4.1 & NR & Singer et $a l^{21}$ \\
\hline OFT: EMO & F2 & C57BL/6], CSS-1 & 91 & 100 & 81.6 & 1.9 & NR & Singer et $a l^{21}$ \\
\hline OFT: OFD & F2 & C57BL/6), CSS-1 & 91 & 100 & 95.5 & 6.7 & NR & Singer et $a l^{21}$ \\
\hline Composite CA & F2 & C57BL6/], DBA2/J & 396 & 99 & 87 & 4.7 & NR & Steinberger et $a l^{22}$ \\
\hline Composite CA and OFT & $\mathrm{F} 2$ & C57BL6/J, DBA2/J & 396 & 99 & 87 & 5.4 & NR & Steinberger et $a l^{22}$ \\
\hline EPM: CAE & F2 & DeFries (H1, H2, L1 L L2) & 1636 & 100 & 80 & 9.4 & 3.1 & Turri et a ${ }^{24}$ \\
\hline EPM: OAE & F2 & DeFries (H1, H2, L1, L2) & 1636 & 100 & 80 & 15.4 & 5.3 & Turri et $a 1^{24}$ \\
\hline EPM: OAT & F2 & DeFries (H1, H2, L1, L2) & 1636 & 100 & 82 & 3.4 & 1.1 & Turri et $a 1^{24}$ \\
\hline LD box: latency & F2 & DeFries (H1, H2, L1, L2) & 1636 & 100 & 80 & 4.9 & 1.7 & Turri et $a 1^{24}$ \\
\hline LD box: light box time & $\mathrm{F} 2$ & DeFries (H1, H2, L1, L2) & 1636 & 100 & 80 & 9.9 & 3.3 & Turri et $a 1^{24}$ \\
\hline LD box: transitions & F2 & DeFries (H1, H2, L1, L2) & 1636 & 100 & 76 & 16.7 & 6.2 & Turri et $a 1^{24}$ \\
\hline OFT: OFA & F2 & DeFries ( $\mathrm{H} 1, \mathrm{H} 2, \mathrm{~L} 1, \mathrm{~L} 2)$ & 1636 & 100 & 74 & 27.3 & 10 & Turri et $\left.a\right|^{24}$ \\
\hline OFT: OFD & F2 & DeFries (H1, H2, L1, L2) & 1636 & 100 & 74 & 14.4 & 5.5 & Turri et $a 1^{24}$ \\
\hline EPM: CAE & F2 & Defries ( $\mathrm{H} 1 \mathrm{~b}, \mathrm{~L} 1 \mathrm{~b})$ & 815 & 100 & 80 & 3.9 & 2.7 & Turri et $a 1^{23}$ \\
\hline EPM: CAE & F2 & Defries $(H 2, L 2)$ & 821 & 100 & 80 & 5.5 & 3.7 & Turri et $a 1^{23}$ \\
\hline EPM: OAE & F2 & Defries $(H 2, L 2)$ & 821 & 100 & 80 & 13.8 & 8.6 & Turri et $a 1^{23}$ \\
\hline EPM: OAE & F2 & Defries (H1b, L1b) & 815 & 100 & 82 & 4 & 3.3 & Turri et $a 1^{23}$ \\
\hline OFT: OFA & F2 & Defries (H1b, L1b) & 815 & 100 & 72 & 12.8 & 10.9 & Turri et $a 1^{23}$ \\
\hline OFT: OFA & $\mathrm{F} 2$ & Defries $(\mathrm{H} 2, \mathrm{~L} 2)$ & 821 & 100 & 74 & 14.8 & 10 & Turri et $a 1^{23}$ \\
\hline OFT: OFD & F2 & Defries (H2, L2) & 821 & 100 & 72 & 7.4 & 5.3 & Turri et $\left.a\right|^{23}$ \\
\hline OFT: OFD & F2 & Defries ( $\mathrm{H} 1 \mathrm{~b}, \mathrm{~L} 1 \mathrm{~b})$ & 815 & 100 & 80 & 7.6 & 5.8 & Turri et $a 1^{23}$ \\
\hline LD box: light time & F2 & Defries $(\mathrm{H} 2, \mathrm{~L} 2)$ & 821 & 100 & 82 & 5.9 & 3.9 & Turri et $\left.a\right|^{23}$ \\
\hline LD box: transitions & $\mathrm{F} 2$ & Defries (H2, L2) & 821 & 100 & 74 & 10.7 & 7.8 & Turri et $a 1^{23}$ \\
\hline LD box: light time & $\mathrm{F} 2$ & Defries $(\mathrm{H} 1 \mathrm{~b}, \mathrm{~L} 1 \mathrm{~b})$ & 815 & 100 & 78 & 4.2 & 3.2 & Turri et $a 1^{23}$ \\
\hline LD box: transitions & F2 & Defries (H1b, L1b) & 815 & 100 & 78 & 6.7 & 5.1 & Turri et $\left.a\right|^{23}$ \\
\hline FC: cue & F2 & C57BL/6], DBA/2] & 479 & 40 & 66.7 & 5.6 & 6.3 & Wehner et $\left.a\right|^{25}$ \\
\hline
\end{tabular}

Presents the evidence in favour of an emotionality locus/loci on mouse chromosome 1.

$\mathrm{BC}=$ backcross; OFT = open-filed test; $\mathrm{EPM}=$ elevated plus maze; LD box = light dark box; $F C=$ fear conditioning; OFA = open-field ambulation; $\mathrm{OFD}=$ open-field defecation; $\mathrm{CT}=$ centre time; $\mathrm{R}=$ rearings; $\mathrm{OAT}=$ open-arm time; $\mathrm{CAT}=\mathrm{closed}$-arm time; $\mathrm{OAE}=\mathrm{open}-\mathrm{arm}$ entries; $\mathrm{CAE}=\mathrm{closed}$ arm entries; $\mathrm{CA}=$ conditioned avoidance.

Consistent with this estimate, several fine-scale loci have now been mapped in this HS stock within the confines of what initially appeared to be a single locus. Talbot et $a l^{37}$ mapped open-field activity and defection (along with a composite measure termed EMO) in 751 of these animals, revealing a conservatively estimated $2 \mathrm{Mb}$ region surrounding the marker D1MIT264 (located at $71.5 \mathrm{cM}$ on chromosome 1). The allele found to increase emotionality was shared by $\mathrm{A} / \mathrm{J}$ and $\mathrm{C} 3 \mathrm{H}$, whereas AKR, RIII and DBA/2 all shared a decreasing allele. At this locus, however, the two strains utilised for the original $\mathrm{F}_{2}$ mapping experiment could not be distinguished (ie QTL with opposite effects were associated with the same allele), indicating that this locus represents an independent effect.
As most marker loci have a small number of alleles, and the genomes of inbred mouse strains are very similar, it can be difficult to establish from which strain each allele originally descended. Consequently, a number of markers are likely to be uninformative, resulting in an inability to map opposing QTL, which associate with the same allele. Where full genealogical history and founder haplotypes are known, this problem can be circumvented by assigning each animal with a probability that a given marker is derived from a given founder strain, and testing the level of association between these probabilities and the phenotype of interest through analysis of variance. This approach was applied to the Boulder $\mathrm{HS}^{38}$ and as expected revealed two QTL; one located between D1MIT103-D1MIT289 


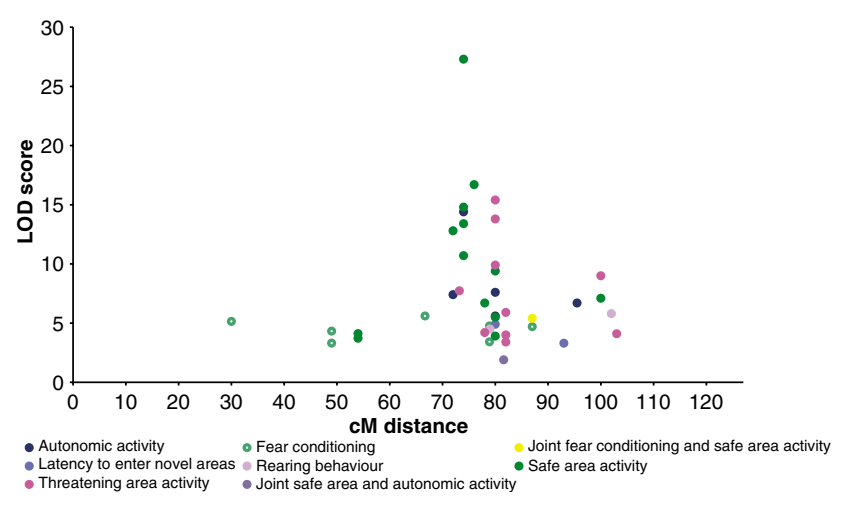

Plot 2 The distribution of significant anxiety-related LOD scores across mouse chromosome 1 by phenotype. This plot illustrates the distribution of genome-wide significant LOD scores (ie linkage peaks) across mouse chromosome 1 , separated by phenotype (where possible using the classifications reported $\mathrm{in}^{35}$ ).

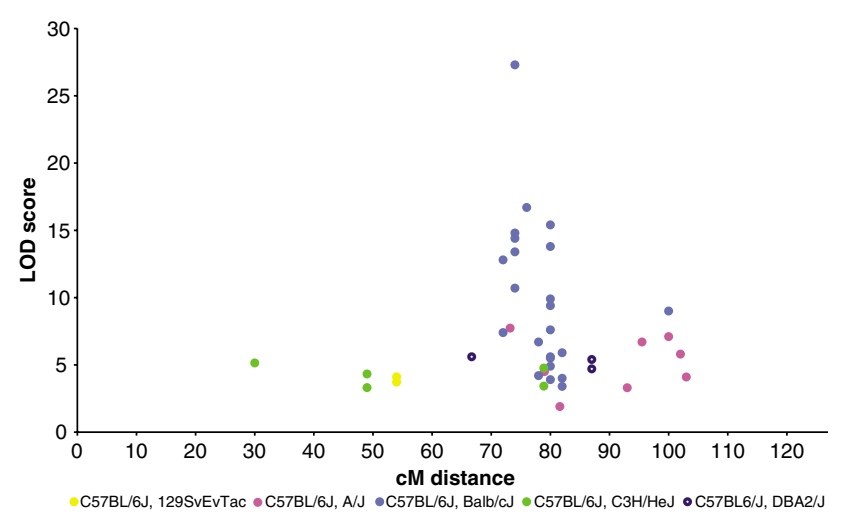

Plot 3 The distribution of significant anxiety-related LOD scores across mouse chromosome 1 by strain contrast. This plot illustrates the distribution of genome-wide significant LOD scores across mouse chromosome 1, separated by strain contrast (ie the types of strains used for mapping).

(73-74.3 cM); a locus which aligns with that previously described in this population, ${ }^{37}$ and the other falling between D1MIT456-D1MIT115 (95.8-99.7 cM).

The second HS population (the Northport HS) was also derived from eight inbred strains $(\mathrm{A} / \mathrm{J}, \mathrm{AKR} / \mathrm{J}, \mathrm{BALB} / \mathrm{cJ}$, $\mathrm{C} 3 \mathrm{H} / \mathrm{HeJ}, \mathrm{C} 57 \mathrm{BL} / 6 \mathrm{~J}, \mathrm{CBA} / \mathrm{J}, \mathrm{DBA} / 2 \mathrm{~J}$ and $\mathrm{LP} / \mathrm{J}$ ), with $\sim 40$ generations of breeding (yielding a slightly reduced mapping resolution relative to the Boulder HS). ${ }^{39}$ Like the Boulder stock, a composite measure of open-field ambulation and defecation (EMO) was also mapped to two loci in this population; with one locus positioned at $82 \mathrm{cM}(-10$ $\log P=5.4)$, and the other at $72 \mathrm{cM}((-10 \log P=4.8)$. While these localisations represent a significant advance in mapping resolution relative to two-strain intercrosses, because of the sheer number of recombination events required to identify single genes, in the majority of cases the QTL intervals remain too large to enable positional cloning.

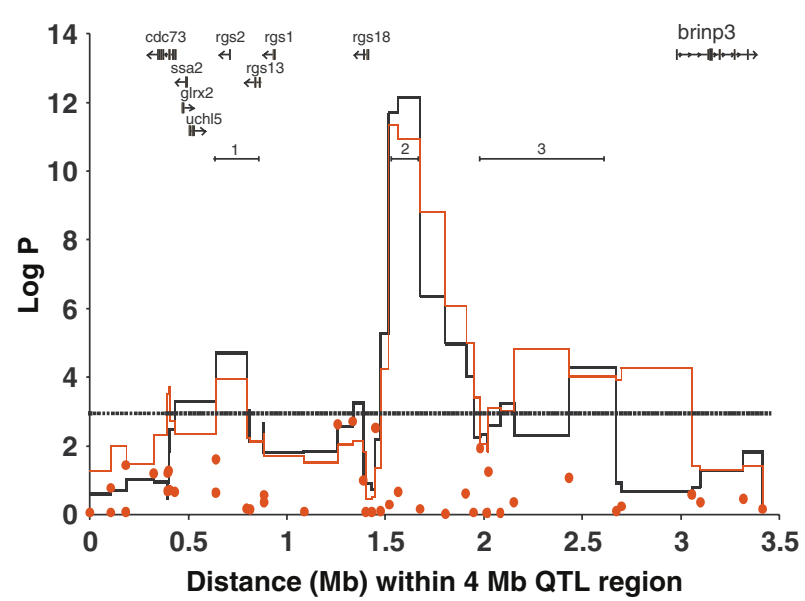

Plot 4 Murine emotionality QTL on chromosome 1. Data derived from the MF1 heterogeneous stock. Single-point ANOVA results are shown as red circles. HAPPY multipoint analysis results are provided in two formats; based on four (black line) or eight progenitors (red line). The 95\% confidence intervals of the three QTL identified are illustrated as horizontal lines numbered 1-3. The Bonferroni corrected $5 \%$ significance threshold is presented as a broken horizontal line.

\section{The use of outbred stocks}

True outbred stocks have one major advantage over HS populations; they have been randomly maintained over an extended number of generations accumulating an unprecedented level of recombination. One such outbred stock, the MF1, was created in the early 1970s by crossing two outbred lines (LACA and CF). Although the genealogy of the MF1 is unknown before this time-point, sequence comparisons have shown a high level of sequence similarity with other inbred strains, such that the MF1 genome can be treated as a mosaic of homology blocks utilising as few as four theoretical progenitors. ${ }^{40}$ As a consequence of this relatively simple genetic architecture, ancestral descent mapping methods can be applied equivalent to those previously used in the HS. In this way emotionality has now been successfully mapped to three apparently independent QTL within the confines of the original HS chromosome 1 locus. The 95\% confidence interval $(\mathrm{CI})$ of peak $1(\log P=5.0)$ covered $0.38 \mathrm{Mb}$ and just two genes; both regulators of G-protein signalling (RGS2 and RGS13). Peak $2(\log P=10.9, C I=0.24)$ was juxtaposed to RGS18, and the CI of peak $3(\log P=4.2)$ covered $0.68 \mathrm{Mb}$ of noncoding sequence (Plot 4 ).

Regulators of G-protein signalling modify the kinetics of G-protein-mediated signalling events, accelerating $\mathrm{G} \alpha$ catalysed GTP hydrolytic turnover by up to 1000 -fold, ${ }^{41}$ without compromising the strength of steady-state signalling. Both RGS2, and to a lesser extent RGS13 are expressed in the brain, ${ }^{42,43}$ and a null mutant is available for RGS2, which exhibits a greater preference for the dark in the light/dark test, and an increased response to the acoustic startle. $^{44}$ Consequently, RGS2 has been pursued as a candidate gene for the chromosome 1 emotionality locus. 


\section{Progressing from QTL to gene}

Identifying the genes underlying QTL action is a major aim of modern genetics. Of the $\sim 2000$ rodent complex trait QTL identified to date, only around 1\% have been successfully cloned, with the majority of these exhibiting uncharacteristically large effect sizes. ${ }^{45}$ Compounding the difficulties associated with detecting small genetic effects, the causative variant may also lie some distance from its target gene, and may lack any association with gene expression (ie due to compensatory mechanisms/a direct effect on protein function).

Circumventing these difficulties, in order to test the candidacy of RGS2 to the chromosome 1 QTL, Yalcin et al ${ }^{40}$ applied a novel method originally designed for use in Drosophila melanogaster; ${ }^{46}$ quantitative complementation (also known as the knockout interaction test). This approach assesses the presence of a genetic interaction between a positional candidate gene and a homologous QTL using a candidate gene mutation (typically null or deficiency) and a simple analysis of variance. By using the RGS2 null mutant which was already available and two inbred strains between which the QTL was known to segregate, Yalcin et $a l^{40}$ were able to show that RGS2 contributes towards emotionality in mice, interacting with the mapped QTL either through allelism or epistasis.

\section{Implications and future directions}

The data presented in this review demonstrate the potential for progression from broad QTL spanning many $\mathrm{cM}$ and hundreds of genes, to single genes of confirmed involvement. However, this confirmation comes with a number of caveats. First, given the methods described above it is impossible to distinguish between allelic and epistatic effects. In order to achieve any degree of confidence that a gene corresponds directly to a QTL further corroborating (preferably functional) evidence is required. Second, this gene represents the tip of a very large iceberg. Given that the QTL containing RGS2 was originally mapped some 9 years prior to the confirmation of RGS2's involvement, it is likely to be some time before the remaining QTL on chromosome 1 (let alone the whole genome) reach a similar level of dissection. However, with the advent of new and more powerful methodologies such as the collaborative cross ${ }^{47}$ (a large reference panel of RILs derived from eight genetically diverse founder strains), whole-genome association and e-QTL (expression-QTL) analysis, accurate QTL localisations should become commonplace - enabling a rapid (and financially viable) shift from QTL mapping to assessments of gene candidacy. In addition, while only mice have been discussed in this review, investigations of QTL concordance across species are also likely to provide valuable insights into QTL localisation and function. The challenge for the future is then to develop economical methods of confirming QTLgene equivalence, and assessing the relevance of these genes to human pathologies.

\section{References}

1 Wallace KJ, Rosen JB: Predator odor as an unconditioned fear stimulus in rats: elicitation of freezing by trimethylthiazoline, a component of fox feces. Behav Neurosci 2000; 114: 912-922.

2 Gosling SD, John OP: Personality dimensions in non-human animals: a cross-species review. Curr Psychol Sci 1999; 8: 69-75.

3 Panksepp J: Psychology. Beyond a joke: from animal laughter to human joy? Science 2005; 308: 62-63.

4 Abril JF, Agarwal P, Alexandersson $\mathrm{M}$ et al: Initial sequencing and comparative analysis of the mouse genome. Nature 2002; 420: 520-562.

5 Wang X, Paigen B: Genetics of variation in HDL cholesterol in humans and mice. Circ Res 2005; 96: $27-42$.

6 Clement Y, Martin B, Venault P, Chapouthier G: Involvement of regions of the 4 th and 7 th chromosomes in the open-field activity of mice. Behav Brain Res 1995; 70: 51-57.

7 DeFries JC, Gervais MC, Thomas EA: Response to 30 generations of selection for open-field activity in laboratory mice. Behav Genet 1978; 8: 3-13.

8 Flint J, Corley R, DeFries JC et al: A simple genetic basis for a complex psychological trait in laboratory mice. Science 1995; 269: $1432-1435$

9 Ossenkopp K-P, Sorenson L, Mazmanian DS: Factor analysis of open-field behavior in the rat (Rattus norvegicus): application of the three-way PARAFAC model to a longitudinal data set. Behavioural Processes 1994; 31: 129-144.

10 Trullas R, Skolnick P: Differences in fear motivated behaviors among inbred mouse strains. Psychopharmacology (Berlin) 1993; 111: $323-331$.

11 Turri MG, DeFries JC, Henderson ND, Flint J: Multivariate analysis of quantitative trait loci influencing variation in anxiety-related behavior in laboratory mice. Mamm Genome 2004; 15: 69-76.

12 Fernandez-Teruel A, Escorihuela RM, Gray JA et al: A quantitative trait locus influencing anxiety in the laboratory rat. Genome Res 2002; 12: 618-626.

13 Crawley JN, Belknap JK, Collins A et al: Behavioral phenotypes of inbred mouse strains: implications and recommendations for molecular studies. Psychopharmacology (Berlin) 1997; 132: 107-124.

14 Mathis C, Paul SM, Crawley JN: Characterization of benzodiazepine-sensitive behaviors in the $\mathrm{A} / \mathrm{J}$ and $\mathrm{C} 57 \mathrm{BL} / 6 \mathrm{~J}$ inbred strains of mice. Behav Genet 1994; 24: 171-180.

15 Valentinuzzi VS, Kolker DE, Vitaterna $\mathrm{MH}$ et al: Automated measurement of mouse freezing behavior and its use for quantitative trait locus analysis of contextual fear conditioning in (BALB/cJ x C57BL/6J)F2 mice. Learn Mem 1998; 5: 391-403.

16 Cohen RM, Kang A, Gulick C: Quantitative trait loci affecting the behavior of $\mathrm{A} / \mathrm{J}$ and $\mathrm{CBA} / \mathrm{J}$ intercross mice in the elevated plus maze. Mamm Genome 2001; 12: 501-507.

17 Gershenfeld HK, Neumann PE, Mathis C, Crawley JN, Li X, Pau SM: Mapping quantitative trait loci for open-field behavior in mice. Behav Genet 1997; 27: 201-210.

18 Gershenfeld HK, Paul SM: Mapping quantitative trait loci for fearlike behaviors in mice. Genomics 1997; 46: 1-8.

19 Kelly MA, Low MJ, Phillips TJ, Wakeland EK, Yanagisawa M: The mapping of quantitative trait loci underlying strain differences in locomotor activity between $129 \mathrm{~S} 6$ and C57BL/6J mice. Mamm Genome 2003; 14: 692-702.

20 Le Roy I, Perez-Diaz F, Cherfouh A, Roubertoux PL: Preweanling sensorial and motor development in laboratory mice: quantitative trait loci mapping. Dev Psychobiol 1999; 34: 139-158. 
21 Singer JB, Hill AE, Nadeau JH, Lander ES: Mapping quantitative trait loci for anxiety in chromosome substitution strains of mice. Genetics 2005; 169: 855-862.

22 Steinberger D, Reynolds DS, Ferris P et al: Genetic mapping of variation in spatial learning in the mouse. J Neurosci 2003; 23: $2426-2433$.

23 Turri MG, Henderson ND, DeFries JC, Flint J: Quantitative trait locus mapping in laboratory mice derived from a replicated selection experiment for open-field activity. Genetics 2001; 158: $1217-1226$

24 Turri MG, Datta SR, DeFries J, Henderson ND, Flint J: QTL analysis identifies multiple behavioral dimensions in ethological tests of anxiety in laboratory mice. Curr Biol 2001; 11: $725-734$.

25 Wehner JM, Radcliffe RA, Rosmann ST et al: Quantitative trait locus analysis of contextual fear conditioning in mice. Nat Genet 1997; 17: 331-334.

26 Yoshikawa T, Watanabe A, Ishitsuka Y, Nakaya A, Nakatani N: Identification of multiple genetic loci linked to the propensity for 'behavioral despair' in mice. Genome Res 2002; 12: 357-366.

27 Caldarone B, Saavedra C, Tartaglia K, Wehner JM, Dudek BC, Flaherty L: Quantitative trait loci analysis affecting contextual conditioning in mice. Nat Genet 1997; 17: 335-337.

28 Gill KJ, Boyle AE: Quantitative trait loci for novelty/stressinduced locomotor activation in recombinant inbred (RI) and recombinant congenic (RC) strains of mice. Behav Brain Res 2005; 161: $113-124$.

29 Owen EH, Christensen SC, Paylor R, Wehner JM: Identification of quantitative trait loci involved in contextual and auditory-cued fear conditioning in BXD recombinant inbred strains. Behav Neurosci 1997; 111: 292-300.

30 Singer JB, Hill AE, Nadeau JH, Lander ES: Mapping quantitative trait loci for anxiety in chromosome substitution strains of mice. Genetics 2005; 169: 855-862.

31 Lander E, Kruglyak L: Genetic dissection of complex traits: guidelines for interpreting and reporting linkage results. Nat Genet 1995; 11: 241-247.

32 Roberts SB, MacLean CJ, Neale MC, Eaves LJ, Kendler KS: Replication of linkage studies of complex traits: an examination of variation in location estimates. Am J Hum Genet 1999; 65: $876-884$

33 Darvasi A, Weinreb A, Minke V, Weller JI, Soller M: Detecting marker-QTL linkage and estimating QTL gene effect and map location using a saturated genetic map. Genetics 1993; 134: 943-951.
34 Kruglyak L, Lander ES: Complete multipoint sib-pair analysis of qualitative and quantitative traits. Am J Hum Genet 1995; 57: 439-454.

35 Henderson ND, Turri MG, DeFries JC, Flint J: QTL analysis of multiple behavioral measures of anxiety in mice. Behav Genet 2004; 34: 267-293.

36 Zhang S, Lou Y, Amstein TM et al: Fine mapping of a major locus on chromosome 10 for exploratory and fear-like behavior in mice. Mamm Genome 2005; 16: 306-318.

37 Talbot CJ, Nicod A, Cherny SS, Fulker DW, Collins AC, Flint J: High-resolution mapping of quantitative trait loci in outbred mice. Nat Genet 1999; 21: 305-308.

38 Mott R, Talbot CJ, Turri MG, Collins AC, Flint J: A method for fine mapping quantitative trait loci in outbred animal stocks. Proc Natl Acad Sci USA 2000; 97: 12649-12654.

39 Demarest K, Koyner J, McCaughran Jr J, Cipp L, Hitzemann R: Further characterization and high-resolution mapping of quantitative trait loci for ethanol-induced locomotor activity. Behav Genet 2001; 31: 79-91.

40 Yalcin B, Willis-Owen SA, Fullerton J et al: Genetic dissection of a behavioral quantitative trait locus shows that Rgs 2 modulates anxiety in mice. Nat Genet 2004; 36: 1197-1202

41 Mukhopadhyay S, Ross EM: Rapid GTP binding and hydrolysis by G(q) promoted by receptor and GTPase-activating proteins. Proc Natl Acad Sci USA 1999; 96: 9539-9544.

42 Ingi T, Aoki Y: Expression of RGS2, RGS4 and RGS7 in the developing postnatal brain. Eur J Neurosci 2002; 15: 929-936.

43 Grafstein-Dunn E, Young KH, Cockett MI, Khawaja XZ: Regional distribution of regulators of G-protein signaling (RGS) 1, 2, 13, 14, 16 , and GAIP messenger ribonucleic acids by in situ hybridization in rat brain. Brain Res Mol Brain Res 2001; 88: 113-123.

44 Oliveira-Dos-Santos AJ, Matsumoto G, Snow BE et al: Regulation of $\mathrm{T}$ cell activation, anxiety, and male aggression by RGS2. Proc Natl Acad Sci USA 2000; 97: 12272-12277.

45 Flint J, Valdar W, Shifman S, Mott R: Strategies for mapping and cloning quantitative trait genes in rodents. Nat Rev Genet 2005; 6 : $271-286$.

46 Long AD, Mullaney SL, Mackay TF, Langley CH: Genetic interactions between naturally occurring alleles at quantitative trait loci and mutant alleles at candidate loci affecting bristle number in Drosophila melanogaster. Genetics 1996; 144: $1497-1510$

47 Churchill GA, Airey DC, Allayee $\mathrm{H}$ et al: The Collaborative Cross, a community resource for the genetic analysis of complex traits. Nat Genet 2004; 36: 1133-1137. 